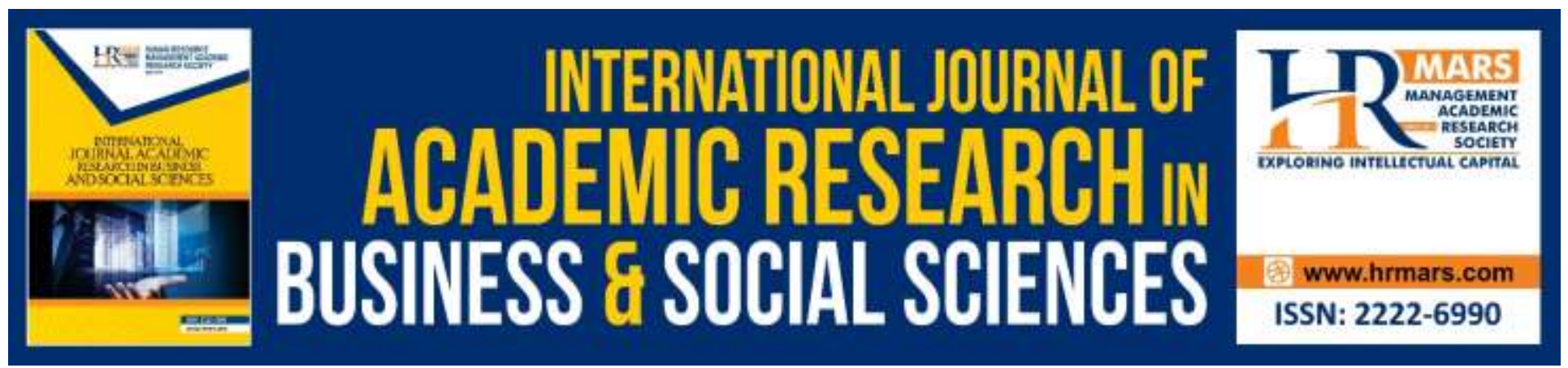

\title{
Self-Talk Intervention Using Video -Imagery: Effects on Under 19 State Soccer Players' Anaerobic Performance
}

\section{Thariq Khan Azizuddin Khan, Zulakbal Abd Karim, Nursahaniza Sato}

To Link this Article: http://dx.doi.org/10.6007/IJARBSS/v9-i7/6118

DOI: $10.6007 /$ IJARBSS/v9-i7/6118

Received: 02 May 2019, Revised: 17 June 2019, Accepted: 30 June 2019

Published Online: 03 July 2019

In-Text Citation: (Khan, Karim, \& Sato, 2019)

To Cite this Article: Khan, T. K. A., Karim, Z. A., \& Sato, N. (2019). Self-Talk Intervention Using Video -Imagery: Effects on Under 19 State Soccer Players' Anaerobic Performance. International Journal of Academic Research in Business and Social Sciences, 9(7), 297-306.

\section{Copyright: (C) 2019 The Author(s)}

Published by Human Resource Management Academic Research Society (www.hrmars.com)

This article is published under the Creative Commons Attribution (CC BY 4.0) license. Anyone may reproduce, distribute, translate and create derivative works of this article (for both commercial and non-commercial purposes), subject to full attribution to the original publication and authors. The full terms of this license may be seen at: http://creativecommons.org/licences/by/4.0/legalcode

Vol. 9, No. 7, 2019, Pg. 297 - 306

Full Terms \& Conditions of access and use can be found at http://hrmars.com/index.php/pages/detail/publication-ethics 


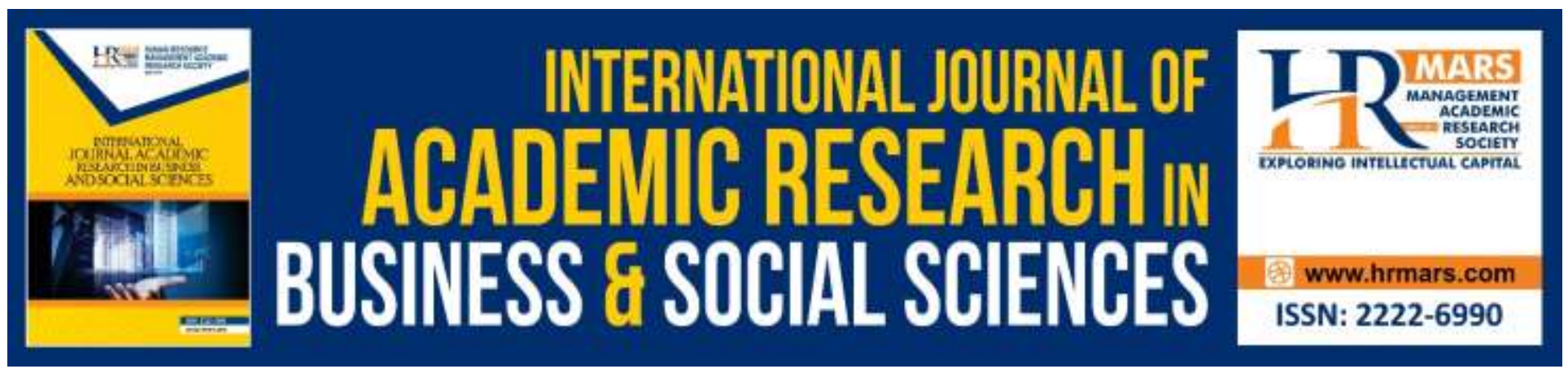

\title{
Self-Talk Intervention Using Video -Imagery: Effects on Under 19 State Soccer Players' Anaerobic Performance
}

\author{
Thariq Khan Azizuddin Khan, Zulakbal Abd Karim, Nursahaniza Sato \\ Faculty of Sport Science and Coaching, Sultan Idris Education University Malaysia
}

\begin{abstract}
The main purpose of this study is to examine the effectiveness of motivational and instructional selftalk cues with video-imagery intervention on Wingate cycle 30-sec anaerobic performance. The participants were 45 male state soccer players employing either one out of three different combination of delivering methods using self-talks cues and video-modelling imagery provided for 4 weeks. A pre-test, intervention, and post-test study design were employed. Using the mixed-design ANOVA, the results shown that participants' who employed self-talk were performing better in anaerobic capacities during the post-test compared to the pre-test $(p<.05)$. Participants' who employed self-talk intervention were also performed better in anaerobic performance compared to control group $(p<.05)$. However, result between the interventions group were found not significant during post-test. In conclusion, self-talk cues employed with imagery video modelling interventions were found to be beneficial to enhance anaerobic capacity, however there is no different of effects on employing either motivational or instructional self-talk cues. Thus, motivational and instructional self-talk interventions were suggested to be employed with imagery and video modelling.
\end{abstract}

\section{Introduction}

The psychological skills namely, imagery, relaxation, goal-setting and self-talk were a frequently method used in the mental skills packages to improve athletes performance (Thelwell and Greenlees, 2003). Psychology skill training that includes self-talk and imagery was also found to improve the performance and one's self-efficacy. For example, according to Hardy, Gammage and Hall (2001), self-talk was a personal dialogue, which the athletes interprets feelings and perceptions, regulates and changes, evaluation and convictions, or give him/herself instructions and reinforcement. There are two main functions of self-talk, namely a cognitive or instructional self-talk and motivational selftalk.

Several studies have been conducted to examine the combined effects of these interventions such as, the effects of self-talk with imagery training (Afsanepurak \& Bahram, 2012), imagery with 
video-modelling training (Azizuddin, Morris \& Marchent, 2015; SooHoo, Takemoto \& McCullagh, 2004), and self-talk with video-modelling training (Barzouka, Sotiroupoulus \& Kiomourtzoglou, 2015) on the specific skills performance. Interventions based video imagery that involves observation learning also shows that there is an increase in performance and personal effectiveness (Clark and Ste-Marie, 2007). Moreover, imagery intervention that coupled with video recording was found to improve performance better than using scrip twriting imagery (Smith \& Holmes, 2004). The use of video intervention in the context of sports was under the symbolic learning and modelling categories. In general modelling is an intervention for any behavior or action that cannot be described verbally yet can be demonstrated visually. For example, according to Zetou, Tzetzis, Vernadakis and Kioumourtzoglou (2002), the use of visual modelling or demonstration was very important tool to teach new motor skills that are usually employed by beginner athletes. Additionally, the use of the video can improve athletic performance and as well as can be used as a routine part of preparation, implementation and current skills, or the half-time interval between games. However, the studies that associated self-talk, imagery and video-modelling in one intervention with the effectiveness of the two main functions of self-talk and imagery namely, a cognitive or instructional and motivational cannot be indentified. Moreover, these combined interventions and the effects on anaerobic performance among athletes is still lacking.

For this reason this study was conducted to measure the effects of the self-talk intervention combined with imagery video modelling on soccer palyers anaerobic performance. In this study combination of theoretical issues in psychology skills trainning (PST) in sports emcompases modelling, motivation, and motor skills performance were examined. Results from this study may provide new information regarding the methods of employing self-talk intervention using imagery dan video modelling to enhance perfomace of anaerobic test.

\section{Method}

\section{Study Design}

This study was a quantitative research by using quasi-experimental study, which is pre-interventionposttest study design.

\section{Population and Sampling}

Forty-five male Perak state soccer players (at least two years of experience of representing state in soccer competition) aged $18 \pm 1$-year-old were recruited. The participants' mean weight, height, and body mass index were $64.7 \pm 8.83$ kilogram, $1.68 \pm 0.05$ meter, and $19.43 \pm 2.4 \mathrm{~kg} / \mathrm{m}^{2}$. Participants' were selected based on purposive sampling, which is all participants' have the same imagery capabilities score from between 150 to 400 .

\section{Instruments}

The instruments used in this study were ergometer cycle, imager abilities questionnaire, self-talk and video-modelling imagery interventions.

Ergometer Bicycle. Peak anaerobic power (watt), total work (kilojoule) and fatigue index (\%) of the participants' were measured by using Corival ergometer bicycle (Lode, Netherlands) within 30 seconds Wingate test protocol with electromagnetic brake mechanism for recording the bicycle 
INTERNATIONAL JOURNAL OF ACADEMIC RESEARCH IN BUSINESS AND SOCIAL SCIENCES Vol. 9, No. 7, July, 2019, E-ISSN: 2222-6990 @ 2019 HRMARS

wheel revolution. Data for each 30-second Wingate test were obtained through the Lode Ergometry Manager System software and Acer computers. Resistance load on the bicycle wheel was automatically set from a manufacturer in the range of $0.7 \mathrm{~kg}$ Torque factor (default setting Lode) of the participants' weight specific for adult males.

Sport Imagery Ability Measure Questionnaire. The Sport Imagery Ability Measure (SIAM; Watt, Morris \& Anderson, 2004). The SIAM was a 48-item self-report questionnaire that examines the experience of 60 seconds of imagery of each of four sport-related scenes on 12 sub-scales associated with imagery

Self-Talk and Imagery Video-modelling. Ergometer bicycle was pedaling by a male model to create the results of peak power (watt) video modelling. The video was recorded using a digital video recorder JVC HD Everio. The video footage then transferred to the laptop and edited by using Microsoft Windows Movie Maker to combine with imagery audio (female voice) for making self-talk with imagery interventions using video-modelling. Video recording editing involves two types of cycling ergometer, which was first video involves instructional and the second one was motivational recordings. Each video-modelling was saved in MP4 form and employed by the participants' on the Samsung Galaxy Tab 10 -inches tablet with screen size display was $65.8 \%$ screen-to-body ratio.

Instructional and Motivational Self-Talk Cues with Imagery-Video Modelling Interventions. The selftalk cue words given for practiced were "Pedal Up and Down Faster!" and "Legs Push Hard!" for instructional, and "I can do it!" and "Keep Going!" for motivational groups. The imagery interventions started with the audio imagery by female voice based on ergometer bicycle pedaling situations. The video modelling footage showed only the leg pedaling model with peak power (watt) results for instructional and the whole body of the model pedaling on an ergometer bicycle for motivational groups. Blank screen was displayed the end of each video recording to allow the participants' to begin their imagery practice.

\section{Procedures of Data Collection}

Before the pre-test, the participants were briefed on the study protocol. Participants' who volunteered to participate were given the consent form to sign and anthropometric information form to be filled.

Pre- test. Before any testing the participants' were instructed to do 10 minutes specific warm-up and stretching. Then, they were seated on ergometer bicycle and the seat was adjusted according to the participants' comfortable position and the clip-on pedals was tightened. The participants' information was computed in Lode Ergometry Manager System software and then they were briefed on 30 seconds Wingate test protocol. The test started with one-minute warm-up on the ergometer bicycle with 70 to 80 revolutions per minute (RPM). Researcher then gives a cue word "go" to started pedal faster as maximum effort or 'all out' within 30 seconds and "stop" to slow down pedalling for two minutes cool-down sesion. All the participants' results such as the peak power, total work, and fatigue index were recorded on participants results form.

Interventions. The instructional and motivational groups employed the interventions for four weeks with training frequencies were three times per week that consists of 12 training session (Kuan, 2014). 
INTERNATIONAL JOURNAL OF ACADEMIC RESEARCH IN BUSINESS AND SOCIAL SCIENCES

Vol. 9, No. 7, July, 2019, E-ISSN: 2222-6990 @ 2019 HRMARS

Post-test. The procedures in the post-test were similar as during the pre-test. The control group was listen to the fast beat tempo songs (140 beats per minute) that were installed on the MP4 and they were freely to chosed the songs from the music lists (Karageorghis \& Priest, 2012). The songs were played on the level between 55 to 70 decibels, which the level of hearings was for normal individual hearings (Job, Cian, Esquivie, Leifflen, Trousselard, Charles, \& Nottet, 2004). The songs were played continuously from the beginning to the end of the test until the cool-down session (Eliakim, Meckel, Nemet \& Eliakim, 2007).

\section{Data Analyses}

As all of the data had been determined normally distributed, anaerobic performance was analyzed using Mixed-Design ANOVA and post hoc Tukey HSD was used for significance differences found.

\section{Results}

The total number of participant who voluntarily participated in this study was 45 males soccer players. Results showed that mean age was $18 \pm 0.5$ years old; mean body weight was $64.7 \pm 8.83 \mathrm{~kg}$ while mean body height was $1.69 \pm 0.05 \mathrm{~m}$. Body Mass Index (BMI) was calculated from the total mean of height and weight which was $19.18 \pm 2.4 \mathrm{~kg} / \mathrm{m}^{2}$. The 30 seconds Wingate test protocols were used to measure the peak power, total work and fatigue index in pre and post-test involved three groups, namely the instructional, motivational and control groups were displayed below.

Table 1 Pre-test and post-test for peak power, total work and fatigue index within 30 seconds Wingate test mean scores

\begin{tabular}{lllllll}
\hline \multirow{2}{*}{ Group } & \multicolumn{2}{l}{ Peak Power (watt) } & \multicolumn{2}{l}{ Total Work (kilojoule) } & \multicolumn{2}{l}{ Fatigue Index (\%) } \\
& $\begin{array}{l}\text { Pre-test } \\
\text { (Mean } \pm \text { SD) }\end{array}$ & Post-test & $\begin{array}{l}\text { Pre-test } \\
\text { (Mean } \pm S D)\end{array}$ & Post-test & $\begin{array}{l}\text { Pre-test } \\
\text { (Mean } \pm \text { SD) }\end{array}$ & Post-test \\
\hline Instruction & $917.52 \pm 171.8$ & $942.22 \pm 206.4$ & $16.85 \pm 1.19$ & $15.80 \pm 1.7$ & $69.88 \pm 17.0$ & $71.74 \pm 13.8$ \\
al & 4 & 9 & 6 & 9 & 5 \\
Motivation & $741.07 \pm$ & $797.45 \pm$ & $14.85 \pm 1.69$ & $13.95 \pm 1.6$ & $63.96 \pm$ & $74.53 \pm$ \\
al & 62.45 & 94.79 & 1 & 9.16 & 9.85 \\
Control & $611.29 \pm$ & $723.24 \pm 103.6$ & $13.26 \pm 2.15$ & $13.02 \pm 1.3$ & $58.88 \pm 11.8$ & $74.04 \pm$ \\
& 77.50 & 9 & 3 & 8 & 8.16 \\
\hline
\end{tabular}




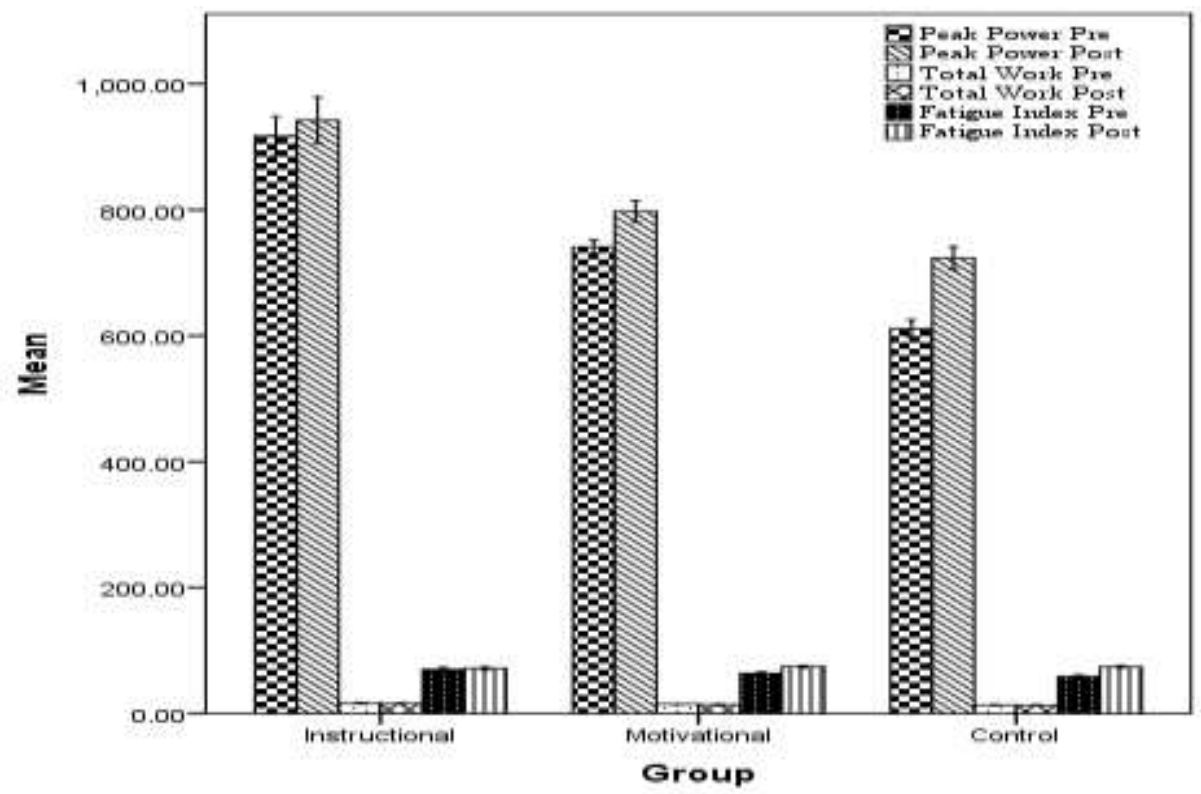

Figure 1 Bar graph in pre-test and post-test for peak power, total work and fatigue index within 30 seconds Wingate test mean scores

Based on Table 1 sthe mean and standard deviation of anaerobic performance were measured based on the peak power, total work and fatigue index involved instructional, motivational and control group, before and after 30 seconds Wingate test. In peak power, there were a significant difference between groups, $F(1,42)=20.83, p<0.000$, partial $\eta^{2}=0.49$, large effect size. There were significant differences $(p<0.05)$ in post hoc Tukey HSD test between groups, suggesting a difference in the effectiveness of the two methods approaches which was an instructional and motivational in peak power. Moreover, there was significant difference in peak power within subjects effect which was in pre-test and post-test, Wilks' Lambda $=.62, F(3,40)=8.04, p=0.000$, partial $\eta^{2}=0.38$, large effect size. These were showed the increases of peak power scores across the two time period.

In total work result, there were a significant differences between groups, $F(1,42)=20.89, p<$ 0.000 , partial $\eta^{2}=0.49$, large effect size. There were significant differences $(p<0.05)$ in post hoc Tukey HSD test between groups, suggesting a difference in the effectiveness of the two methods approaches which was an instructional and motivational in total work. Furthermore, there was significant difference in total work within subjects effect which was in pre-test and post-test, Wilks' Lambda $=.62, F(3,40)=8.04, p=0.000$, partial $\eta^{2}=0.38$, large effect size. These were showed buy the reduction of total work scores across the two time period. For the interaction between time and group, there was no significant difference which was Wilks' Lambda $=.80, F(6,80)=1.54, p=0.177$, partial $\eta^{2}=.10$, moderate effect size.

In fatigue index result there were no significant differences between groups, $F(1,42)=0.83$, $p>0.000$, partial $\eta^{2}=0.04$, small effect size. There were no significant differences $(p>0.05)$ also in post hoc Tukey HSD test between groups, suggesting no difference in the effectiveness of the two methods approaches which was an instructional and motivational in fatigue index. However, there were significant difference in fatigue index within subjects effect which was in pre-test and post-test, 
Wilks' Lambda $=.62, F(3,40)=8.04, p=0.000$, partial $\eta^{2}=0.38$, large effect size. These were showed the increases of fatigue index scores across the two time period. For the interaction between time and group, there were no significant difference, Wilks' Lambda $=.80, F(6,80)=1.54, p=0.177$, partial $\eta^{2}=.10$, moderate effect size.

\section{Discussion}

Based on the findings, there were statistically significant differences among the three groups ( $p$ $<0.05$ ) and also across the two time periods $(p<0.05)$, the pre and post tests. However, only the instructional group gives a major impact and increased the score of peak power and total work. For fatigue index score again, there was no significant difference $(p>0.05)$ among the three groups. However, there is an increased fatigue index score $(p<0.05)$ across two time periods pre and post test for all three groups. This indicates that the anaerobic capacity in instructional group was higher than the control and motivational group. Anaerobic capacity can be defined as the amount of work done or energy produced in the anaerobic process during a short period of time and high-intensity training is complete. In other words, the anaerobic capacity is the ability of an individual to survive in business activity, repeated short-term (up to 90 seconds) at a maximum or near-maximum (Foran, 2001).

Results from this study also indicate that interventions incorporate self-talk, imagery and video-modeling had a positive effect particularly on participant's who employed instructional cues. Basically, the self-talk and imagery in the form of instructional help an individual get information more precisely about something more specific skills to improve performance. In this study, videomodeling has been used as an additional tool for conveying information at a skill more clearly, and this facilitates the study participants to replicate the treatment, as shown by the model in the video and by the use of cue self-talk and imagery are instructional. In line with Theodorakis (2000) study, that the effectiveness of self-talk is dependent on the 'nature' of the task carried out. Instructional self-talk is more beneficial to the characteristics of assignments in the form of accuracy for the implementation of these skills can be assisted through increased focus attention on the technical side of implementation. For motivational self-talk was beneficial to the characteristics of assignments in the form of strength and durability for the implementation of these skills can be assisted through increased trade.

In the study of Ram, Riggs, Scaling and Landers (2007) has stated that there are significant differences between groups that combined imagery and video-modeling, and suggest that the student or new athletes (novice), intervention modeling can contribute to better performance compared to that obtained from the purely physical exercise. In addition, an improvement in performance is also dependent on the climate of motivation or a positive social environment that influence and modulate motivation of individuals involved in the performance of a skill. It is also in line with the Social Cognitive Theory adapted from Bandura (1997) puts the network structure of cause and effect that depend on agents behavior of individual effort itself, the personal belief of individuals, and the environmental conditions that feedback whether positive or negative. According to Karaba-Jakovljevic, Popadić-Gacesa, Grujic, Barak and Drapsin (2007), bio-feedback techniques such as verbal encouragement and visual feedback is often used to enhance performance. 
In the current study, the positive feedback is video-modeling that showed model testing Wingate 30 seconds and feedback can also be known as visual feedback and verbal encouragement was helped by the positive self-talk. Both these feedback techniques either in the form of instructional or motivational research has helped participants' to better trust to themselves in 30 seconds Wingate test perform more effectively. In fact, both of these techniques also work with imagery exercises help to shape or reshape the treatment of a skill demonstrated by the model in the video-modeling it in their minds before the image is applied in real situations and skills. KarabaJakovljevic et al. (2007) also stated that, motivation plays an important role in all the tests that require a comprehensive energy and maximum effort. When assessing the capabilities and requires maximum effort, it is very important to achieve a high level of motivation. Thus, the results obtained as a result of motivation will help reflect the maximum individual effort.

\section{Conclusion}

In conclusion, this study shows that the intervention of combined self-talk, imagery and videomodeling whether in the form of instructional and motivational has affected to the increase in peak power and total work but no impact on the fatigue index. It was also explained by Rymal, Martini and Ste-Marie (2010) that the pre-recording imagery scripts which are also equipped with video-modeling can provide an athlete with information relevant to the performance of the sport skills that can lead to improved performance.

Results from this study may provide new body of knowledges regarding self-efficacy theory and modelling theory. New technology devices namely andriods, smart phone and tab were found beneficial to deliver audio self-talk imagery and video modelling. In summary, information provided in modelling theory should be consider and examine before any self-talk and imagery training been employed.

\section{Acknowledgements}

This research was supported by Research Acculturation Grant Scheme Malaysia (2014-0119-106-72RAGS) and Universiti Pendidikan Sultan Idris Malaysia (UPSI).

\section{References}

Afsanepurak, S. A., \& Bahram, A. (2012). The Effect of self-talk and imagery on Motor performance in adolescents. International Research Journal of Applied \& basic Sciences, 3(3), 601-607.

Khan, A. T. K., Morris, T., \& Marchant, D. (2015). Portable devices to delivering imagery and modelling among netball player's: A qualitative study. Journal of Sports Science and Physical Education, 3.50-64.

Bandura, A. (1997). Self-efficacy: The exercise of control. New York: Freeman.

Bar-Or, O. (1987). The Wingate anaerobic test an update on methodology, reliability and validity. Sports Medicine, 4(6), 381-394.

Barzouka, K., Sotiropoulos, K., \& Kioumourtzoglou, E. (2015). The effect of feedback through an expert model observation on performance and learning the pass skill in volleyball and motivation. Journal of Physical Education and Sport, 15(3), 407. 
INTERNATIONAL JOURNAL OF ACADEMIC RESEARCH IN BUSINESS AND SOCIAL SCIENCES Vol. 9, No. 7, July, 2019, E-ISSN: 2222-6990 @ 2019 HRMARS

Clark, S. E., \& Ste-Marie, D. M. (2007). The impact of self-as-a-model interventions on children's self-regulation of learning and swimming performance. Journal of Sports Sciences, 25(5), 577-586.

Eliakim, M., Meckel, Y., Nemet, D., \& Eliakim, A. (2007). The effect of music during warm-up on consecutive anaerobic performance in elite adolescent volleyball players. International journal of sports medicine, 28(4), 321-325.

Foran, B. (2001). High-performance sports conditioning. Champaign, IL: Human Kinetics.

Hardy, J., Gammage, K., \& Hall, C. (2001). A descriptive study of athlete self-talk. Sport Psychologist, 15(3), 306-318.

Inbar, O., Bar-Or, O., \& Skinner, J. S. (1996). The Wingate anaerobic test. Human Kinetics.

Job, A., Cian, C., Esquivie, D., Leifflen, D., Trousselard, M., Charles, C. \&Nottet, J. B. (2004). Moderate variations of mood / emotional states related to alterations in cochlear otoacoustic emissions and tinnitus onset in young normal hearing subjects exposed to gun impulse noise. Hearing Research. 193, 31-38.

Karaba-Jakovljevic, D., Popadic-Gacesa, J., Grujic, N., Barak, O., \& Drapsin, M. (2007). Motivation and motoric tests in sports. Medicinski pregled, 60(5-6), 231-236.

Karageorghis, C. I., \& Priest, D. L. (2012). Music in the exercise domain: a review and synthesis (Part I). International review of sport and exercise psychology, 5(1), 44-66.

Kuan, G. (2014). Music, imagery training, and sports performance (Doctoral thesis, Victoria University). Retrieved from http://vuir.vu.edu.au/24835/1/Garry\%20Kuan.pdf. On February 12, 2016.

Parra, J., Cadefau, J. A., Rodas, G., Amigo, N., \& Cusso, R. (2000). The distribution of rest periods affects performance and adaptations of energy metabolism induced by high-intensity training in human muscle. Acta Physiologica Scandinavica, 169(2), 157-165.

Ram, N., Riggs, S. M., Skaling, S., Landers, D. M., \& McCullagh, P. (2007). A comparison of modelling and imagery in the acquisition and retention of motor skills. Journal of Sports Sciences, 25(5), 587-597.

Rymal, A. M., Martini, R., \&Ste-Marie, D. M. (2010). Self-regulatory processes employed during selfmodelling: a qualitative analysis. The Sport Psychologist, 24(1), 1-15.

Smith, D., \& Holmes, P. (2004). The effect of imagery modality on golf putting performance. Journal of Sport and Exercise Psychology, 26(3), 385.

SooHoo, S., Takemoto, K. Y., \& McCullagh, P. (2004). A comparison of modelling and imagery on the performance of a motor skill. Journal of Sport Behavior, 27(4), 349.

Stathis, C. G., Febbraio, M. A., Carey, M. F., \& Snow, R. J. (1994). Influence of sprint training on human skeletal muscle purine nucleotide metabolism. Journal of Applied Physiology, 76(4), 1802-1809.

Thelwell, R. C., \& Greenlees, I. A. (2003). Developing competitive endurance performance using mental skills training. Sport Psychologist, 17(3), 318-337.

Theodorakis, Y., Weinberg, R., Natsis, P., Douma, I., \& Kazakas, P. (2000). The effects of motivational versus instructional self-talk on improving motor performance. Sport Psychologist, 14(3), 253-271. 
INTERNATIONAL JOURNAL OF ACADEMIC RESEARCH IN BUSINESS AND SOCIAL SCIENCES Vol. 9, No. 7, July, 2019, E-ISSN: 2222-6990 @ 2019 HRMARS

Watt, A. P., \& Morris, T., Andersen, M. B. (2004). Issues in the development of a measure of imagery ability in sport. Journal of mental imagery, 28(3 \& 4), 149-180.

Zetou, E., Tzetzis, G., Vernadakis, N., \& Kioumourtzoglou, E. (2002). Modelling in learning two volleyball skills. Perceptual and motor skills, 94(3c), 1131-1142.

Zupan, M. F., Arata, A. W., Dawson, L. H., Wile, A. L., Payn, T. L., \& Hannon, M. E. (2009). Wingate anaerobic test peak power and anerobic capacity classifications for men and women intercollegiate athletes. The journal of Strength \& Conditioning Research, 23(9), 2598-2604. 